\title{
Evaluation of APSIM - Maize model under different sowing dates at Samaru, Nigeria
}

\author{
A.M. YAMUSA ${ }^{1 *}$ and F.M.AKINSEYE ${ }^{2}$ \\ ${ }^{1}$ Meteorological Service Unit, Institute for Agricultural Research, Ahmadu Bello University, Zaria Nigeria \\ ${ }^{2}$ Department of Meteorology Federal University of Technology Akure, Nigeria \\ *Corresponding Author: amyamusa@abu.edu.ng
}

\begin{abstract}
APSIM - maize model was validated with the experimental data on three maize cultivars (Sammaz 33, Sammaz 37 and Sammaz 27) sown on three different dates during 2015 wet season at the Institute for Agricultural Research Samaru Zaria Nigeria (Lat. 7R" 38'N, Long. 11R" 11'E Lat. 686m). For the testing efficiency of the model performance, $R^{2}$, RMSE and RMSEn was computed. RMSEn between observed and simulated values by APSIM for grain yield was lowest $(5.4 \%)$ for Sammaz 33 cultivar as compared to Sammaz $37(10.5 \%)$ and Sammaz 26 (27.6\%). Similar results were obtained for the other parameters, with Sammaz 33 out yielding the other two cultivars. The observed values under second sowing date showed better performance of days to flowering, physiological maturity and leaf area index for all the varieties. The grain yield performance were higher under first sowing date. The results led to the conclusion that APSIM model is efficient in simulating maize growth and development in arid environment of Samaru.
\end{abstract}

Keywords: Agricultural productivity, APSIM, crop simulation, maize, rainfall.

Samaru belongs to the Nigerian Northern Guinea Savannah of the West African semi-arid region with a mean annual precipitation of about $1011 \mathrm{~mm}$ with coefficient of variation of 16 per cent (Oluwasemire and Alabi, 2004). The area has a uni-modal pattern of rainfall that starts in May, peaks in July/August when frequent heavy rainfall is experienced before finally terminating in October. The area is characterized by high evapotranspiration, always higher than the rainfall from October to May thus determining the growing period of crops.

Agriculture which is the mainstay of the rural livelihoods and National Gross Domestic Product (GDP) of most African countries including Nigeria is the most vulnerable to climate variability and change. In Nigeria, maize which is one of the most widely grown cereals is equally the most vulnerable to climate variability. Until recently, the bulk of maize grain produced in Nigeria was from the southwest zone of the country but there has been a dramatic shift of the grain production to the savannah which can be regarded as the maize belt of Nigeria (Ikem and Amusa, 2004). Maize is most productive in this area because sun shine is adequate and rainfall is moderate (Obi, 1991).

Crop modelling is an effective tool in understanding and analysing the consequences of management options under variable climatic conditions. A model like APSIM (Agricultural Production Systems Simulator) has been in used in simulating maize growth and development for a wide range of climatic conditions (Archontoulis et al., 2014) and management practices (Fosu-Mensah et al., 2012). APSIM model has been used for various applications in India, viz. yield gap analysis of maize (Mohanty et al. 2017), climate change impact studies on wheat and soybean (Mohanty et al., 2015; 2017). APSIM has had limited use in Sub-Saharan Africa due to the scarcity of suitable input data for model parameterization, testing, and application (Whitbread et al.,2010).

This work aimed at investigating the reliability of rainfall onset predictions and their effects on three maize varieties and validating APSIM-Maize model so as to develop intervention packages for maize production in the semi-arid zone of Samaru, Nigeria.

\section{MATERIALS AND METHODS}

\section{Experimental details}

The experiment was conducted during the 2015 wet season at the Institute for Agricultural Research (IAR) field in Samaru (Latitude $11^{\circ} 11^{\prime} \mathrm{N}$ and Longitude $7^{\circ} 38^{\prime} \mathrm{E}$ ) and laid out as a split - plot arrangement in a randomized complete block design (RCBD) with three replications. 


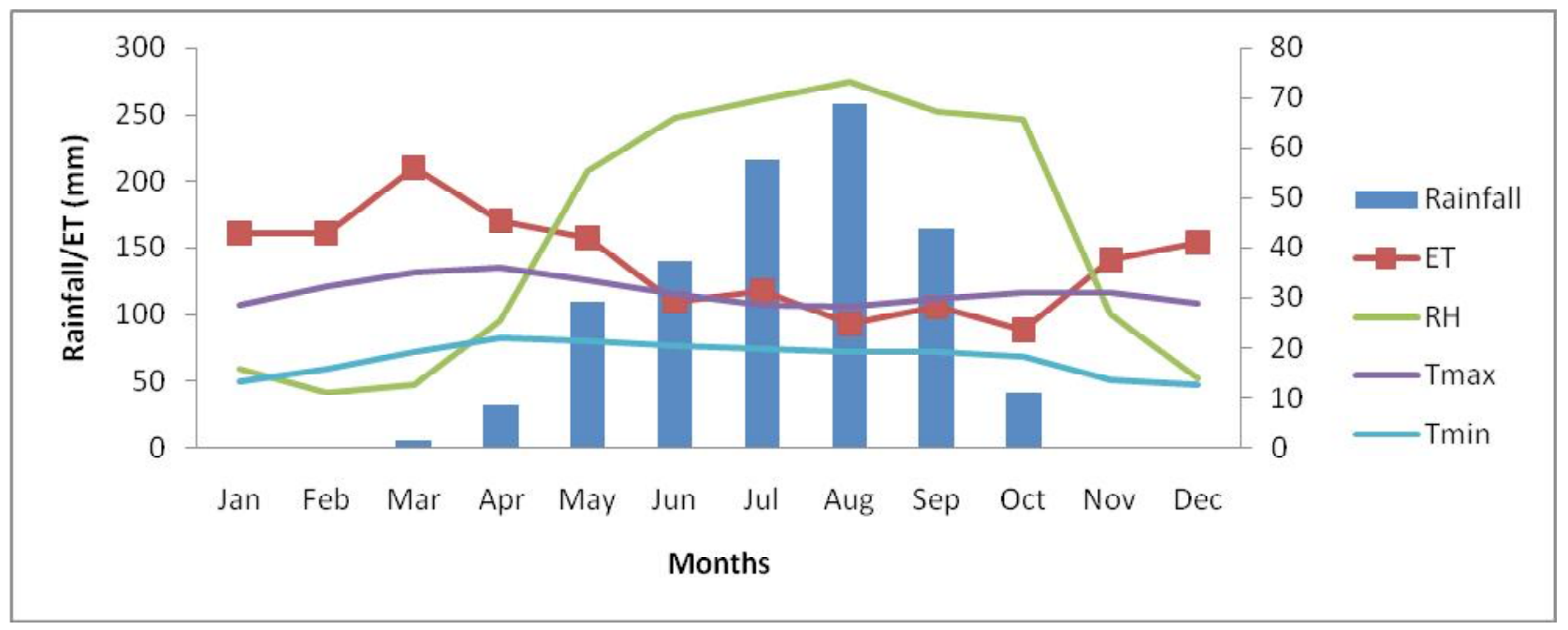

Fig. 1: Long term climatic data over Samaru

Main plot treatments: sowing date (SD1, SD2 and SD3):

SD1: $29 / 5 / 2015$, was based on the rainfall onset prediction by the Nigerian Meteorological Agency (NIMET, 2015) which predicted its first planting window to be from $19^{\text {th }}-26^{\text {th }}$ May of 2015 ,

SD2: 10/6/2015, based on Omotosho et al.(2000); "The beginning of the first two rains totaling $20 \mathrm{~mm}$ or more, within 7 days, followed by 2 to 3 weeks each with at least 50 per cent of the weekly crop water requirement"

SD3: $27 / 6 / 2015$, based on farmers sowing dates which normally begins from the $2^{\text {nd }}$ week of June.

Sub plot treatment (Variety - 3):

V1: Sammaz 33 (Extra early maturing variety)

V2: Sammaz 37 (Early maturing variety)

V3: Sammaz 26 (Medium maturing variety)

\section{Land preparation, farm management and data collection}

The field was divided into three equal blocks according to planting dates. Each block was divided into three equal replications with nine plots in each replication.

Establishment records (date of sowing, emergence $(>50 \%)$, thinning, plant population and successive tip appearance) of the crops on main stem were taken. Within each plot, a net plot was marked out and plant stands in each net plot was selected and marked for observation. Days to 50 per cent emergence and tasselling, number of leaves per plant, number of cobs per plot at harvest, cobs weight per plot at harvest, 100 grain weight and date of harvest were recorded. The growth measurements were carried out at two weeks intervals commencing from 4 weeks after emergence. This was determined using the method adopted by (Stickler et al., 1961). One plant was taken from each plot outside the designated final harvest area and the length and breadth of leaves of each plant was recorded. The average of these length and breadth was multiplied by a factor of 0.80 to obtain the leaf area of each plot.

\section{APSIM Maize simulation model}

The data collected from the field experiments was used for APSIM model evaluation. Specific cultivar coefficients for the genotypes used in this experiment was not in the list of genotypes available with the model, therefore, evaluation was done using basic information for the cultivar coefficients provided with the model. The cultivar coefficients were adjusted, until main growth and development stages were simulated within 10 per cent of the measured values.

To evaluate the performance of the APSIM model, $\mathrm{R}^{2}$, absolute and normalized root mean squared error (RMSE and RMSEn) (Wilmot et al., 1985) were calculated as follow.

Absolute RMSE $=\left(\Sigma(\mathrm{Pi}-\mathrm{Oi})^{2} / \mathrm{n}\right)^{0.5}$

$\operatorname{RMSEn}=100\left(\Sigma(\mathrm{Pi}-\mathrm{Oi})^{2} / \mathrm{n}\right)^{0.5} / \mathrm{O}_{\text {mean }}$

Where $\mathrm{Pi}$ is the simulated value, Oi is the observed value and $n$ is the number of measurements. RMSEn is stated in percentage of simulated amounts than observed amounts. According to the above descriptions RMSEn $<10$ per cent is excellent, 10 per cent $<$ RMSEn $<20$ per cent is well, 20 per cent $<$ RMSEn $<30$ per cent is moderate, RMSEn $>30$ per cent is weak (Rinaldy et al., 2003).

\section{RESULTS AND DISCUSSION}

\section{Climatic condition of the study area}

The mean monthly climatic data of fifty years (1963 
Table 1: Final settings of APSIM-Maize module after calibration and evaluation for three varieties

\begin{tabular}{lccccc}
\hline Parameter & Source & Units & Sammaz 33 & Sammaz 37 & Sammaz 26 \\
\hline Thermal time accumulation & & & & & \\
Duration-emergence to end of Juvenile & Calibrated & ${ }^{\circ} \mathrm{C}$ day & 218 & 280 & 400 \\
Duration-flag leaf to flowering stage & Calibrated & ${ }^{\circ} \mathrm{C}$ day & 170 & 170 & 170 \\
Duration-flowering to start of grain filling & Calibrated & ${ }^{\circ} \mathrm{C}$ day & 600 & 580 & 540 \\
Duration-flowering to seed ripening & Literature & ${ }^{\circ} \mathrm{C}$ day & 1 & 1 & 1 \\
Photoperiod & & & & 12.5 & 12.5 \\
Daylength photoperiod to inhibit flowering & Default & $\mathrm{H}$ & 12.5 & 24 \\
Daylength photoperiod for insensitivity & Default & $\mathrm{H}$ & 12.5 & 24 & 6 \\
Base temperature & Literature & ${ }^{\circ} \mathrm{C}$ day & 6 & 6 & 35 \\
Optimum temperature & Default & ${ }^{\circ} \mathrm{C}$ day & 35 & 35 & 6 \\
\hline
\end{tabular}

Table 2: Simulated and observed phenological, morphological and yield data of different varieties under three dates of sowing

\begin{tabular}{|c|c|c|c|c|c|c|c|c|c|c|c|}
\hline \multicolumn{2}{|c|}{ Flowering(DAS) } & \multicolumn{2}{|c|}{ Maturity (DAS) } & \multicolumn{2}{|c|}{ Leaf No. } & \multicolumn{2}{|c|}{ LAI } & \multicolumn{2}{|c|}{ Grain yield $\left(\mathrm{kg} \mathrm{ha}^{-1}\right)$} & \multicolumn{2}{|c|}{ Biomass yield $\left(\mathrm{kg} \mathrm{ha}^{-1}\right)$} \\
\hline Obs. & Sim. & Obs. & Sim. & Obs. & Sim. & Obs. & Sim. & Obs. & Sim. & Obs. & Sim. \\
\hline
\end{tabular}

Sammaz 33 (Extra early maturing maize variety)

$\begin{array}{lllllllllllll}\text { SD1 } & 56 & 55 & 89 & 84 & 16.3 & 16.8 & 1.68 & 1.69 & 3433 & 3307 & 3616 & 3468 \\ \text { SD2 } & 58 & 53 & 98 & 84 & 15.8 & 16.9 & 1.97 & 2.17 & 2866 & 3042 & 4162 & 5043 \\ \text { SD3 } & 56 & 58 & 90 & 87 & 15.3 & 13.7 & 1.93 & 2.36 & 2600 & 2777 & 3992 & 2665 \\ \text { RMSE } & 0.05 & & 0.06 & & 1.2 & & 0.27 & & 161 & & 923 \\ \text { RMSEn } & 5.7 \% & & 6.3 \% & & 7.3 \% & & 4.9 \% & & 5.4 \% & & 23.5 \%\end{array}$

Sammaz 37 (Early maturing maize variety)

$\begin{array}{lllllllllllll}\text { SD1 } & 63 & 64 & 95 & 96 & 16.9 & 17.6 & 1.74 & 1.94 & 3017 & 3191 & 4376 & 3201 \\ \text { SD2 } & 65 & 62 & 98 & 95 & 16.3 & 17 . & 1.77 & 1.88 & 3006 & 2848 & 3878 & 2598 \\ \text { SD3 } & 65 & 67 & 98 & 98 & 16.5 & 16.9 & 1.64 & 1.75 & 2333 & 2506 & 3872 & 2259 \\ \text { RMSE } & 2.1 & & 1.8 & & 1.03 & & 0.46 & & 291 & & 1368 \\ \text { RMSEn } & 3.4 \% & & 2.0 \% & & 6.2 \% & & 2.8 \% & & 10.5 \% & 33.8 \%\end{array}$

Sammaz 26 (Medium maturing maize variety)

\begin{tabular}{lllllllllllll} 
SD1 & 84 & 82 & 110 & 112 & 17.2 & 17.9 & 1.83 & 1.59 & 2644 & 2689 & 4922 & 3486 \\
SD2 & 82 & 81 & 111 & 110 & 14.8 & 13.7 & 1.74 & 1.54 & 3179 & 2592 & 4652 & 3564 \\
SD3 & 84 & 85 & 113 & 112 & 15.7 & 12.3 & 1.81 & 1.43 & 2066 & 1643 & 5423 & 2283 \\
RMSE & 0.02 & & 0.03 & & 2.1 & & 0.28 & & 724 & & 2089 \\
RMSEn & $1.7 \%$ & & $1.3 \%$ & & $14.4 \%$ & & $5.3 \%$ & & $27.6 \%$ & & $41.3 \%$ \\
\hline
\end{tabular}

-2012) collected from Samaru Meteorological Unit of the Institute for Agricultural Research are presented in Fig. 1. Rainfall pattern in the area is uni-modal starting in May, peaking in July/August when frequent heavy rainfall is experienced before finally terminating in October. The highest monthly rainfall of $250 \mathrm{~mm}$ is in August. The maximum temperature $\left(32^{\circ} \mathrm{C}\right)$, minimum temperature $\left(18^{\circ} \mathrm{C}\right)$, sun shine hours (6.5hrs/day) are highest in April.

\section{APSIM - Maize model performance}

Genotype specific parameters were generated from the experiment for three cultivars of maize Sammaz 33 (V1), Sammaz 37 (V2) and Sammaz 26 (V3) (Table 1). Some of the parameters were taken from literature and other as default values. The observed and simulated phenological, morphological and yield data of three varieties under 3 dates of sowing are presented in Table 2. The results revealed that 
the simulated days to flowering, days to physiological maturity, leaf area index and grain yield of three varieties sown on three dates closely matched with the observed values. In case of variety Sammaz 33 the observed values under second sowing date (SD2) were higher day to flowering, days to physiological maturity, leaf area index and biomass yield in comparison to other sowing dates. The grain yield was however higher under the first sowing date (3433 $\left.\mathrm{kg} \mathrm{ha}^{-1}\right)$. Variety Sammaz 37 produced highest grain yield $\left(3017 \mathrm{~kg} \mathrm{ha}^{-1}\right)$ and biomass yield $\left(4376 \mathrm{~kg} \mathrm{ha}^{-1}\right)$ under the first sowing date (SD1). While growth parameter (LAI) was higher (1.77) under second sowing date (SD2). The medium maturing maize variety Sammaz 26 took highest number of days (113) for maturity under late sown condition (SD3). The biomass was also highest $\left(5423 \mathrm{~kg} \mathrm{ha}^{-1}\right)$ under SD3, however the grain yield was highest (3179 $\left.\mathrm{kg} \mathrm{ha}^{-1}\right)$ under second sowing date (SD2). Among the three cultivars the maximum grain yield was observed in extra early maturing variety Sammaz 33, while the maximum biomass was observed in medium maturing variety Sammaz 26.

The results on simulated values of different phenological, morphological and yield parameters (Table 2) under different dates of sowing for 3 varieties of maize show very close relationship with the observed values, as indicated by statistical parameters RMSE and RMSEn. In most of the cases, the RMSEn (\%) values were less than 10, except in case of biomass yield. APSIM model under estimated the biomass under all the dates of sowing as well as for all the varieties with RMSEn (\%) ranging between 23.5 and 41.3 . Even the grain yield of variety Sammaz 26 was under estimated by the model (Table 2).

\section{CONCLUSIONS}

The results indicated that the simulation achieved poor results with late sowing dates (farmers sowing dates) and therefore the model should be used with caution within the limit of experimental error to simulate growth and yield over wide range of planting dates, cultivars and climatic scenarios for adaptation strategies.

To ensure minimization of the effect of rainfall variability on crop yield in general and maize in particular, at the study area, sensitization visits and other awareness programs on the seasonal forecasts of onset dates and cessation of rainy season by The Nigerian Meteorological Agency (NIMET) is recommended.

The results also led to the conclusion that APSIM model is efficient in simulating maize growth and development in semi - arid environment of Samaru. It can be used in decision making to mitigate the effect of climatic risk, selection of suitable varieties and management options for sustainable agriculture.

\section{REFERENCES}

Archontoulis SV, MiguezFE and Moore K.J.(2014). Evaluating APSIMmaize, soil water, soil nitrogen, manure, and soil temperature modules in the midwestern United States. Agron. J., 106:1025-1040.

Fosu-Mensah B.Y., MacCarthy D.S., Vlek PLG and Safo, E.Y. (2012). Simulating impact of seasonal climatic variation on the response of maize (Zea mays L.) to inorganic fertilizer in sub-humid Ghana. Nutrient Cycling Agroecos., 94:255-271.

Iken, J.E and Amusa, N.A. (2004). Maize Research and Production in Nigeria. African J., Biotech., 3 (6) :302307.

Mohanty, M., Sinha, N.K., Hati, K.M., Sammi Reddy, K. and Chaudhary, R.S. (2015). Elevated temperature and carbon dioxide concentration effects on wheat productivity in Madhya Pradesh: a simulation study. $J$. Agrometeorol., 17(2):185-189.

Mohanty, M., Sinha, N.K., Patidar, R.K., Somasundaram, J., Chaudhary, R.S., Hati, K.M., Sammi Reddy,K., Prabhakar, M., Srinivasrao, C. and Patra,A.K. (2017). Assesment of maize (Zea May L.) productivity and yield gap analysis using simulation modeling in subtropical climate of central India. J. Agrometeorol., 19(4):342-345.

Mohanty, M., Sinha, N.K., Mcdermid, S.P., Chaudhary, R.S., Hati, K.M., Somasundaram, J., Lenka, S., Patidar, R.K., Prabhakar, M., Srinivasrao, C. and Patra, A.K. (2017). Climate change impacts vis-à-vis productivity of soybean in vertisol of Madhya Pradesh. J. Agrometeorol., 19(1):10-16.

NIMET (2015). Nigerian Meteorological Agency Seasonal Rainfall Prediction and Climate Review.

Obi, IU (1991). Maize: Its agronomy, diseases, pests and food values optimal computer solutions limited, Enugu $208 \mathrm{p}$.

Oluwasemire, K.O. andAlabi, S.O. (2004). Ecological Impact of Changing Rainfall Pattern, Soil Processes and Environmental Pollution in Nigerian Sudan and Northern Guinea Savanna Agro-Ecological Zones. Nigerian J. Soil Res., 5:23-31.

Omotosho, J.B., Balogun A.A. and Ogunjobi K. (2000). 
Predicting Monthly and Seasonal Rainfall, Onset and Cessation of the Rainy Season in West Africa using only Surface Data. Int. J., Climatol. 20: 865-880.

Rinaldy, Losavio, M.N. and Flagell, Z. (2003). Evalvation of OILCROP SUN model for sunflower in southern Italy. Agric. Sys. 78:17.30.

Sticler, F. C., Wendt, S. and Paul A.W. (1961). Leaf area determination in three low-input millet fields in Nigeria. W/A. Agron. J., 82:813-819.
Whitbread, A.M., Robertson M.J., CarberryP.S. and Dimes, J.P. (2010). How farming systems simulation can aid the development of more sustainable smallholder farming systems in southern Africa. European J. Agron., 32:5158.

Willmott, C.J., Ackleson, S.G., Davis, R.E., Feddema, J.J., Klink, K.M., Legates, D.R., O’Connell, J., Rowe, C.M. (1985). Statistics for the evaluation and comparison of models. J. Geophys. Res., 90 (C5):8995-9005. 